\title{
Interleukin-1 $\alpha$, soluble interleukin-2 receptor, and IgG concentrations in cystic fibrosis treated with prednisolone
}

\author{
P Greally, M J Hussain, D Vergani, J F Price
}

\begin{abstract}
The cytokines interleukin-1 and interleukin-2 participate in the inflammatory response, and may contribute to hypergammaglobulinaemia $G$ and the development of lung injury in cystic fibrosis. Anti-inflammatory treatment with corticosteroids may attenuate this response. The effect of a 12 week course of oral prednisolone on spirometry and serum concentrations of interleukin-1 $\alpha$ (IL-1 $\alpha)$, soluble interleukin-2 receptor (sIL-2R), and IgG was investigated in 24 children with cystic fibrosis. Prednisolone was administered, in a double blind and placebo controlled manner, at an initial dose of $2 \mathrm{mg} / \mathrm{kg}$ daily for 14 days and tapered to $1 \mathrm{mg} / \mathrm{kg}$ on alternate days for 10 weeks. The treated group $(n=12)$ experienced an increase in forced expiratory volume in one second and forced vital capacity at 14 days, however, these changes were smaller at 12 weeks. In the treated group, change in pulmonary function was associated with decreased serum IgG and cytokine concentrations. Prednisolone suppresses serum concentrations of these cytokines, which may participate in the inflammatory response, the excessive synthesis of IgG, and airflow obstruction observed in cystic fibrosis patients.

(Arch Dis Child 1994; 71: 35-39)
\end{abstract}

Defective chloride conductance renders the cystic fibrosis airway epithelia susceptible to bacterial invasion despite the presence of vigorous local inflammatory responses. Chronic colonisation with Pseudomonas aeruginosa heightens this inflammatory process. Histology of the affected airway reveals a dense inflammatory infiltrate in which granulocytes predominate. ${ }^{1}$ Their lysosomal enzymes may cause local tissue damage, degradation of structural proteins in the bronchial wall, and cleavage of components necessary for bacterial opsonisation. ${ }^{2-4}$ However, significant numbers of activated $\mathrm{T}$ lymphocytes and B cells are also observed. ${ }^{5}$ Complex interactions between these cells and pulmonary macrophages produce stimuli which may orchestrate and intensify the dense neutrophil infiltrate.

Interleukin (IL)- $1 \alpha$ and IL-2 are proinflammatory cytokines produced in response to infectious and immunological stimuli. IL- $1 \alpha$ is mainly derived from mononuclear phagocytes.
It is chemotactic for granulocytes and induces their degranulation. ${ }^{67} \mathrm{IL}-1 \alpha$ is one of the earliest cytokines produced in response to antigen and may initiate the release of a cascade of other cytokines including IL-2, IL-6, IL-8, and TNF- $\alpha{ }^{89}$ IL-2 is derived from activated $T$ lymphocytes and is chemotactic for $T$ and $B$ cells. ${ }^{7}$ IL-1 $\alpha$ upregulates IL-2 receptors on mononuclear cells and can induce IL-2 release by T cells. ${ }^{7}$ Soluble IL-2 receptor (sIL-2R) is shed after stimulation of mononuclear cells by IL-2 and is one indicator of $\mathrm{T}$ cell activation. ${ }^{10} \mathrm{IL}-1 \alpha$ and IL-2 may act synergistically to attract $B$ cells to sites of inflammation in cystic fibrosis and promote their differentiation into mature plasma cells capable of producing immunoglobulin. ${ }^{11}$

Hypergammaglobulinaemia $G$ frequently accompanies chronic endobronchial infection in cystic fibrosis and is associated with a poorer prognosis. ${ }^{12}$ It is unclear whether this merely reflects the heavy bacterial load within the cystic fibrosis lung or whether it in itself represents a mechanism by which immunologically mediated lung injury can occur. Immune complex formation, particularly with pseudomonas antigens, and the subsequent local activation of complement have been implicated in the pathogenesis of lung injury in cystic fibrosis. ${ }^{13-16}$ The generation of the complement component $\mathrm{C} 5 \mathrm{a}$ in cystic fibrosis lung fluids may add to the chemoattractant force for granulocytes and correlates with their elastase activity in lavage fluid. ${ }^{17}$ The concept of immunologically mediated lung injury in cystic fibrosis has led investigators to examine the effects of anti-inflammatory drugs.

Corticosteroids are potent anti-inflammatory agents. Clinical studies of their efficacy in cystic fibrosis patients have yielded conflicting results. Though three weeks' treatment with prednisolone (20-30 mg daily) failed to relieve airflow obstruction in severely affected adults with cystic fibrosis (median forced expiratory volume in one second $\left(\mathrm{FEV}_{1}\right) 27 \%$ predicted), ${ }^{18}$ alternate day prednisone, taken for four years, significantly reduced serum IgG concentration and respiratory morbidity in children with cystic fibrosis. ${ }^{19}$

The precise biochemical mechanism of action of corticosteroids in vivo remains uncertain. Corticosteroids can inhibit the release of IL-1 $\alpha$ by monocytes, the production of IL-2 by T lymphocytes, and expression of IL-2 receptors on mononuclear cells in vitro. ${ }^{20-23}$ These properties may contribute to their anti-inflammatory effect in patients with 
cystic fibrosis. We have previously demonstrated that serum concentrations of IL- $1 \alpha$ and sIL-2R are higher in cystic fibrosis patients than in controls and that they correlate with serum immunoglobulin concentrations. ${ }^{24}$ In the present study, we investigated what effect oral prednisolone had on serum IL- $1 \alpha$, sIL-2R, and IgG concentrations in the context of their effect on pulmonary function in clinically stable cystic fibrosis patients.

\section{Methods}

Twenty four patients aged 5.5-19.5 years (mean 11.9 years) with confirmed cystic fibrosis (sweat sodium $>70 \mathrm{mmol} / \mathrm{l}$ ) and established respiratory disease $\left(\mathrm{FEV}_{1}<85 \%\right.$ predicted for age, sex, and height) participated in the study. Prednisolone was administered in a randomised, double blind, and placebo controlled manner. The actively treated group received soluble prednisolone $2 \mathrm{mg} / \mathrm{kg}$ body weight daily for 14 days (maximum dose $40 \mathrm{mg}$ ) and then $1 \mathrm{mg} / \mathrm{kg}$ body weight on alternate days for the next 10 weeks (maximum dose $40 \mathrm{mg}$ ). Soluble prednisolone and identical inert placebo tablets were supplied by Glaxo. Excluded from the study were patients taking oral/inhaled corticosteroids, sodium cromoglycate, or theophylline. Those with acute respiratory infection, evidence of allergic bronchopulmonary aspergillosis, or concurrent disease precluding steroid usage were also excluded. Outcome measures were $\mathrm{FEV}_{1}$ and forced vital capacity (FVC) as measured by spirometry, and serum IL-1 $\alpha$, sIL-2R, and IgG. Assessments were performed at baseline, 14 days, and 12 weeks. Alterations in spirometry were expressed as change in percentage predicted. Atopic state was determined by performing skin prick tests to 10 common inhalant allergens including Aspergillus fumigatus. Isolated responses to $A$ fumigatus were not considered as indicative of atopy. Informed consent was obtained from patients or their parents in all cases and the study was approved by the hospital's ethics committee. A full physical examination was performed at each visit. Specific steroid side effects (hypertension, hypernatraemia, hypokalaemia, fluid retention, and glucose intolerance) were carefully sought. Blood pressure, weight, serum electrolyte and blood glucose concentrations were checked each time. Given its half life (approximately four weeks), IgG was only measured at baseline and 12 weeks, by nephelometry.

Table 1 Details of prednisolone and placebo groups at baseline

\begin{tabular}{lccl}
\hline & $\begin{array}{c}\text { Predisolone } \\
(n=12)\end{array}$ & $\begin{array}{c}\text { Placebo } \\
(n=12)\end{array}$ & Significance \\
\hline Mean (range) age in years & $12 \cdot 3(5 \cdot 5-19 \cdot 5)$ & $11 \cdot 5(7-16 \cdot 5)$ & NS $^{\star}$ \\
M:F & $6: 6$ & $6: 6$ & NS \\
Mean (SEM) weight in kg & $33 \cdot 6(3 \cdot 4)$ & $31 \cdot 4(2 \cdot 6)$ & NS $^{\star \star}$ \\
Mean (SEM) height in cm & $142(6 \cdot 3)$ & $135(3 \cdot 9)$ & NS $^{\star \star}$ \\
$P$ aeruginosa & 6 & 8 & SS $^{\star}$ \\
Atopy & 7 & 7 & NS $^{\star}$ \\
Sensitivity to A fumigatus & 5 & 4 & NS $^{\star \star}$ \\
Mean (SEM) \% predicted FEV & $54(6 \cdot 0)$ & $57(5 \cdot 6)$ & NS $^{\star \star}$ \\
Mean (SEM) \% predicted FVC & $66(3 \cdot 5)$ & $72(5 \cdot 9)$ &
\end{tabular}

${ }^{\star} \chi^{2}$ test with Yates's correction. ${ }^{\star \star}$ Unpaired Student's $t$ test.
Table 2 Mean (SEM) \% predicted FEV and FVC before, during, and at the end of treatment in prednisolone and placebo groups

\begin{tabular}{llll}
\hline & Baseline & 14 Days & 12 Weeks \\
\hline FEV & & & \\
$\quad$ Prednisolone & $54(6 \cdot 0)$ & $62(5 \cdot 9) \ddagger^{\star \star}$ & $60(5 \cdot 7) \dagger^{\star}$ \\
$\quad$ Placebo & $57(5 \cdot 6)$ & $56(5 \cdot 2)$ & $55(5 \cdot 9)$ \\
FVC & & & \\
$\quad$ Prednisolone & $66(3 \cdot 5)$ & $76(4 \cdot 1) \dagger^{\star \star}$ & $70(4 \cdot 2) \dagger$ \\
Placebo & $72(5 \cdot 9)$ & $70(5 \cdot 4)$ & $69(6 \cdot 1)$ \\
& & &
\end{tabular}

Unpaired Student's $t$ test: ${ }^{\star} \mathrm{p}<0.05,{ }^{\star \star} \mathrm{p}<0.01$.

Paired Student's $t$ test: $\nmid \mathrm{p}<0.05, \neq \mathrm{p}<0.01$.

Cytokine assays were performed on coded specimens by a scientist (MJH) who was unaware of patients' identity, treatment received, and the order in which samples were collected. Immune reactive concentrations of IL- $1 \alpha$ were assayed in serum using a two site enzyme linked immunosorbent assay (ELISA). Specimens were analysed in duplicate and unknown values read from standard curves constructed using recombinant IL- $1 \alpha$. The lower limit of detection of IL-1 $\alpha$ was $10 \mathrm{pg} / \mathrm{ml}$. Immunoreactive concentrations of sIL-2R were measured using two antibodies directed against different epitopes of the TAC portion of the IL-2 receptor in a modification of an ELISA method described elsewhere. ${ }^{10}$ The assay sensitivity was $200 \mathrm{IU} / \mathrm{ml}$. Interassay and intra-assay coefficients of variation for both ELISAs were less than $10 \%$.

\section{STATISTICS}

The Minitab statistical package (Minitab Inc) was used to perform the analysis. Normality scores were calculated for spirometric values, cytokine and IgG concentrations which confirmed that they were all normally distributed. Results are expressed as mean (SEM). Paired Student's $t$ tests were employed to assess the significance of change from baseline values in each group. Unpaired Student's $t$ tests were then used to compare changes in spirometry and cytokine concentration in treated and placebo groups; results are expressed as mean changes with $95 \%$ confidence intervals $(95 \% \mathrm{CI})$ for the difference between the groups.

\section{Results}

Twelve patients received prednisolone and 12 received placebo. The groups were comparable with respect to age, baseline lung function, atopic state, weight, height, and colonisation with $P$ aeruginosa (table 1 ). There was a tendency in the placebo group for lung function to deteriorate over the study period, these changes were not significant ( $\mathrm{p}>0.4$, paired Student's $t$ test). At 14 days, mean change in $\%$ predicted $\mathrm{FEV}_{1}$ (prednisolone $v$ placebo, difference $(95 \% \mathrm{CI})$ ) was $+7 \cdot 7 v-1 \cdot 0$, difference $8.7(-15$ to -2$)$; $\mathrm{p}<0.02$, and in FVC was $+10.4 v-2.4$, difference $12.8(-21$ to -4.5$) ; \mathrm{p}=0.005$. At 12 weeks mean change in \% predicted $\mathrm{FEV}_{1}$ was $+6.3 v-1.8$, difference $8 \cdot 1 \quad(-16$ to $-0.4) ; \mathrm{p}<0.04$, and in FVC was $+4.7 v-2 \cdot 0$, difference $6.7(-17$ to $1 \cdot 0) ; \mathrm{p}=0.08$ (table 2 ). 

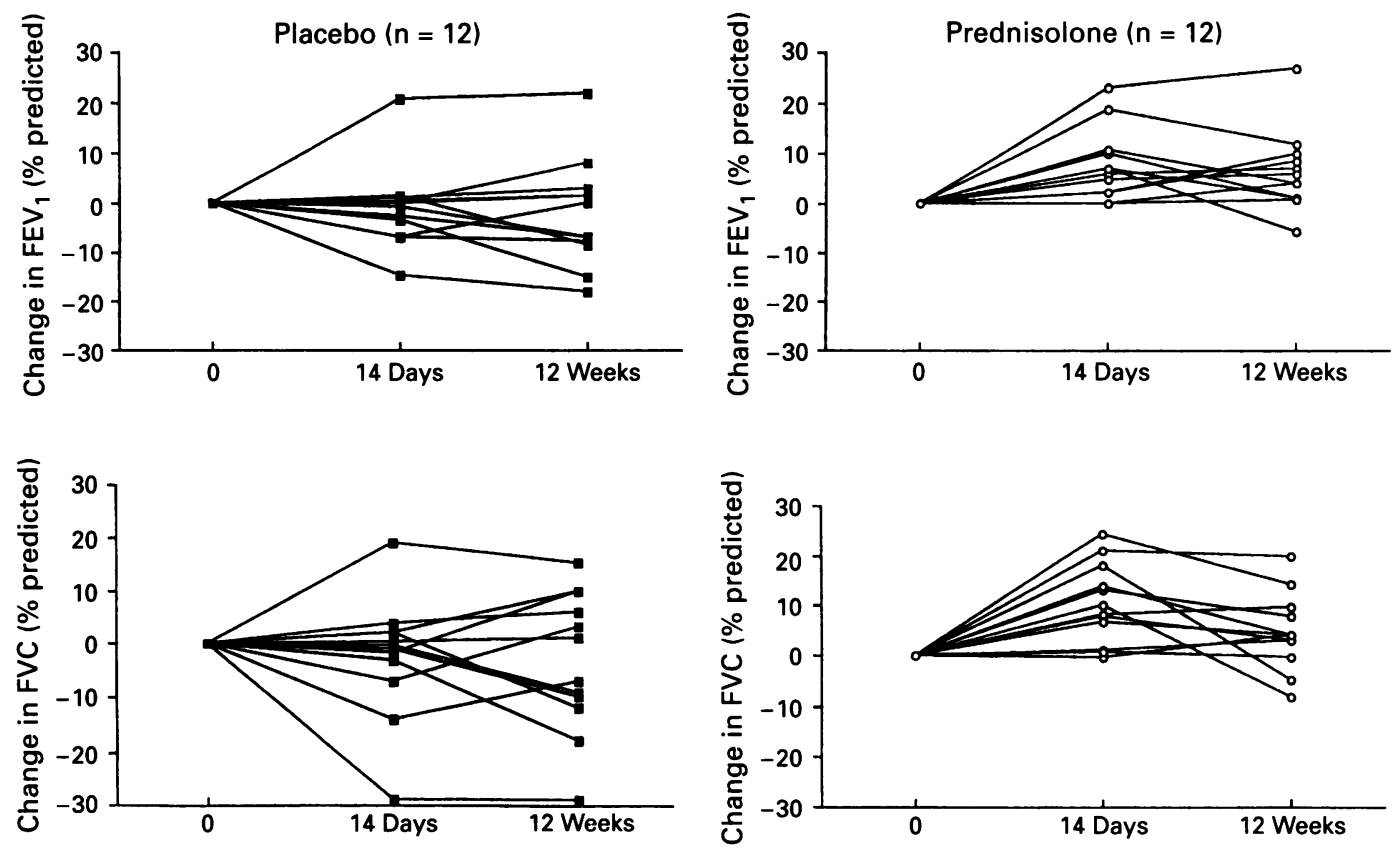

Individual changes from baseline in $F E V_{1}$ and $F V C$ as $\%$ predicted. Filled squares=placebo and open circles = prednisolone.

In some, a tendency for both parameters to revert to baseline was observed on the alternate day regimen (figure).

Baseline cytokine concentrations did not differ significantly in either group (table 3). At 14 days mean change (prednisolone $v$ placebo, difference $(95 \% \mathrm{CI}))$ in $\mathrm{IL}-1 \alpha(\mathrm{pg} / \mathrm{ml})$ was $-205 v-2$, difference 203 ( -475 to 69 ); $\mathrm{p}>0.05$, and sIL-2R (IU $/ \mathrm{ml})$ was $-200 v+18$, difference 218 (47 to 382 ); $\mathrm{p}<0.02$. At 12 weeks mean change in IL- $1 \alpha$ was $-250 v+64$, difference 314 ( -569 to -58$) ; \mathrm{p}=0.01$, and sIL-2R was $-178 v-38$, difference 140 (24 to 303); $\mathrm{p}<0.05$.

Mean (SEM) serum IgG concentrations $(\mathrm{g} / \mathrm{l})$ in the treated group were $17 \cdot 8(1 \cdot 5)$ at baseline and $12.3(1.5)$ at 12 weeks compared with concentrations of the placebo group at baseline of $18.0(3.1)$ and $18.9(3.1)$ at 12 weeks. Mean change in IgG (prednisolone $v$ placebo, difference $(95 \% \mathrm{CI})$ ) was -5.5 $v+0.9$, difference 6.4 (3.9 to 8.7); $\mathrm{p}<0.001$. No acute lower respiratory tract infections occurred in either group. One patient developed hyperglycaemia (blood glucose $17 \mathrm{mmol} / \mathrm{l}$ ) at the end of the high dose regimen which settled rapidly on alternate day prednisolone. No other steroid related side effects were noted. No disseminated or opportunistic infections occurred in the treated groups. Although not a primary outcome measure, there was a tendency for the actively treated group to gain more weight (mean change in $\mathrm{kg}$, prednisolone $v$ placebo
(95\% CI)) over the 12 week study period compared with those who received placebo was $+1 \cdot 5 v+0 \cdot 4$, difference $1 \cdot 1(-2 \cdot 1$ to $0 \cdot 4)$; $\mathrm{p}>0.05$.

\section{Discussion}

Our results demonstrate that high dose prednisolone can affect airflow obstruction in children with cystic fibrosis who are clinically stable. The placebo group exhibited a slight tendency to deterioration. These changes were neither clinically nor statistically significant and did not exaggerate the changes in the treated group (see table 2, paired analysis). The responsiveness of pulmonary function and circulating cytokines to corticosteroids appeared to be independent of an individual's atopic predisposition, sensitisation to $A$ fumigatus, chronic pseudomonas infection, or impairment of lung function at baseline. Although, the mean changes in $\mathrm{FEV}_{1}$ and FVC were smaller at 12 weeks in the treated group, they are likely to be biologically meaningful, given that the annual rate of decline in $\mathrm{FEV}_{1}$ approaches $3 \%$ of predicted. ${ }^{25}$ The trend for treated patients to revert to baseline lung function on the alternate day regimen suggests a degree of dose responsiveness (figure). One might have expected these changes to be accompanied by reversion of serum IL-1 $\alpha$ and sIL-2R concentrations to baseline. However, falls in serum IgG concentration occurred which may have

Table 3 Mean (SEM) IL-1 $\alpha$ and sIL-2R before, during, and at the end of treatment

\begin{tabular}{|c|c|c|c|c|c|c|}
\hline & \multicolumn{2}{|l|}{ Baseline } & \multicolumn{2}{|l|}{14 Days } & \multicolumn{2}{|l|}{12 Weeks } \\
\hline & Prednisolone & Placebo & Prednisolone & Placebo & Prednisolone & Placebo \\
\hline $\begin{array}{l}\mathrm{IL}-1 \alpha(\mathrm{pg} / \mathrm{ml}) \\
\text { sIL-2R (IU/ml) }\end{array}$ & $\begin{array}{l}561(141) \\
412(91 \cdot 2)\end{array}$ & $\begin{array}{l}617(177) \\
367(50 \cdot 4)\end{array}$ & $\begin{array}{l}356(100) \\
212(32 \cdot 6)^{\star} \ddagger\end{array}$ & $\begin{array}{l}615(178) \\
385(64 \cdot 2)\end{array}$ & $\begin{array}{l}311(91 \cdot 4)^{\star} \dagger \\
234(28 \cdot 2)^{\star} \dagger\end{array}$ & $\begin{array}{l}681(197) \\
329(45 \cdot 1)\end{array}$ \\
\hline
\end{tabular}

Unpaired Student's $t$ test: ${ }^{\star} \mathrm{p}<0.05$. Paired Student's $t$ test: $\neq \mathrm{p}<0.05, \neq \mathrm{p}<0.01$. 
reduced immune complex formation ${ }^{26}$ and perhaps in turn, complement activation and the subsequent generation of harmful complement degradation products. Both soluble immune complexes and complement byproducts are powerful inducers of IL-1 secretion by pulmonary macrophages. Increases in unmeasured mediators implicated in cystic fibrosis lung injury (neutrophil elastase, leukotriene $\mathbf{B}_{4}$, other cytokines or adhesion molecules) at the 12 weeks interval cannot be excluded. Although a causal relationship cannot be confirmed, our results suggest that IL- $1 \alpha$ and IL-2 are involved in the orchestration of the inflammatory response and the enhanced synthesis of IgG which accompany airflow obstruction in patients with cystic fibrosis.

Serum was used to detect immunoreactive concentrations of IL-1 $\alpha$ and sIL-2R and therefore we cannot exclude the possibility of cytokine release during the clotting process ex vivo. However, we have previously demonstrated that children with cystic fibrosis have significantly higher serum cytokine concentrations than normal controls ${ }^{24}$ suggesting that the clotting mechanism per se does not underlie our findings. It is also important to distinguish immunoreactivity from biological activity. Naturally occurring inhibitors of IL- $1 \alpha$ have been described and the soluble IL-2 receptor may itself compete with membrane boundIL-2 receptors for IL-2. ${ }^{27} 28$ In the presence of chronic infection and inflammation, these factors may limit immunologically mediated lung damage by moderating these exaggerated protective responses. Therefore, in the absence of a confirmatory bioassay, we can only speculate as to the biological activity of the IL-1 $\alpha$ and SIL-2R that we have detected. The finding that improvements in pulmonary function are accompanied by falls in cytokine concentration suggest that the immunoreactivity detected represents biologically important cytokine activity.

The putative mechanism of action of corticosteroids is the induction of lipocortin, a polypeptide that antagonises phospholipase $A_{2}$. This was believed to limit the release of arachidonic acid from membrane phospholipids and reduce the substrate for both cyclo-oxygenase and 5-lipoxygenase pathways. However, this mechanism has not yet been confirmed by relevant in vivo studies in patients with asthma, cystic fibrosis, or normal controls. ${ }^{29-31}$ Corticosteroids act at many other levels of the inflammatory response. Perhaps more relevant to human disease states is their ability to suppress cytokine release, thereby blocking communication between cells of the immune system. Many of the reported anti-inflammatory effects of corticosteroids could be attributable to a corticosteroids effect on cytokine production and release. Moreover, it has been shown that many cytokine genes share a consensus sequence in their promoter region which codes for corticosteroids responsive elements which enable enhancement or attenuation of gene transcription. ${ }^{32}$ Vital interactive sites on immune complexes, IgG, and complement may be cleaved by proteases derived from neutrophils and $P$ aeruginosa and may result in defective opsonophagocytosis. ${ }^{33}$ These molecules may still retain their ability to promote both cytokine release by pulmonary macrophages and neutrophil chemotaxis. ${ }^{34}$ Thus, the inflammatory cycle is perpetuated without clearance of the offending organism. Corticosteroids appear to attenuate unrestrained airway inflammation in cystic fibrosis and may alter airflow obstruction without predisposing patients to opportunistic or disseminated infection.

Short courses of systemic steroids can change pulmonary function and reduce systemic inflammatory cytokine immunoreactivity in clinically stable cystic fibrosis patients. Long term administration of prednisone $(2 \mathrm{mg} / \mathrm{kg}$ on alternate days) is associated with an unacceptably high incidence of side effects. ${ }^{35}$ Data regarding safety and efficacy of a lower dose $(1 \mathrm{mg} / \mathrm{kg}$ on alternate days $\times 4$ years, US National Collaborative Study) have not been published, and therefore the long term administration of corticosteroids at this dose cannot be recommended. However, our results raise important questions regarding their anti-inflammatory effect in patients with cystic fibrosis, which require further investigation. Firstly, they may represent a useful adjunct to the treatment of infective exacerbations during periods when inflammatory activity can be expected to be greatest. Secondly, more potent and topically active steroid compounds may have beneficial effects on lung function, which permit their long term use, without causing systemic toxicity. Finally, the earlier administration of topical steroids to younger children without overt lung disease who have silent inflammatory activity ${ }^{36}$ may delay the inevitable decline that occurs in pulmonary function.

We wish to thank the Cystic Fibrosis Trust for funding PG.

1 Bedrossian CWM, Greenberg SD, Singer DB, Hansen JJ, Rosenberg HS. The lung in cystic fibrosis: a qualitative study including the prevalence of pathological findings among different age groups. Hum Pathol 1976; 7: 195-204.

2 Suter S, Schaad UB, Roux L, Nydegger UE, Wladvogel FA. Granulocyte neutral protease and pseudomonas elastase as possible causes of airway damage in patients with cystic fibrosis. F Infect Dis 1984; 149: 523-31.

3 Johnson U, Ohlsson K, Olsson I. Effect of granulocyte proteases on complement components. Scand $\mathcal{F}$ Immunol 1976; 5: 421-6.

4 Bruce MC, Poncz L, Klinger J, Stern R, Tomashefski JF, Dearborn DG. Biochemical and pathological evidence for Dearborn DG. Biochemical and pathological evidence for proteolytic destruction of lung connective tissue
fibrosis. $A m$ Rev Respir Dis 1985; 132: 529-35.

5 Azzawi M, Johnston PW, Majumdar S, Kay AB, Jeffery PK. T-lymphocytes and activated eosinophils in airway mucosa in fatal asthma and cystic fibrosis. Am Rev Respir Dis 1992; 145: 1447-82.

6 Dinarello CA. Interleukin-1. Rev Infect Dis 1984; 6: 51-95. 7 Male D, Champion B, Cooke A, Owen M. Cytokines. In: Advanced immunology. 2nd Ed. London: Gower Medical Publishing, 1991: 11.3-11.5.

8 Espevik T, Waage A, Faxvaag A, Shalaby MR. Regulation of interleukin-2 and interleukin-6 production from $T$ cells: involvement of interleukin- $1 \beta$ and transforming growth factor $\beta$. Cell Immunol 1990; 126: 47.

9 Strieter R, Chensue SW, Basha MA, et al. Human alveolar macrophage gene expression of IL-8 by lipopolysaccharide, tumour necrosis factor $\alpha$ and interleukin-1 $\beta$. Am $\mathcal{F}$ Respir Cell Mol Biol 1990; 2: 321-5. 
10 Roubin LA, Kurman C, Fritz ME, et al. Soluble interleukin2 receptors are released from activated human lymphoid cells in vitro. $\mathcal{F}$ Immunol $1985 ; 135$ : $3172-7$

11 Klaus GGB. B-cell activation. In: Rickwood D, Male D, eds. B-lymphocytes. Oxford: IRL at Oxford University Press, 1990:4.4.

12 Wheeler WB, Williams M, Matthews WJ, Colten HR. Progression of cystic fibrosis lung disease as a function of Progression of cystic fibrosis lung disease as a function of serum immunoglobulin G levels:

13 Schiotz PO, Nielsen H, Hoiby N, Glikmann G, Svehag SE. Immune complexes in sputum of patients with cystic
fibrosis suffering from chronic Pseudomonas aeruginosa fibrosis suffering from chronic Pseudomonas aeruginosa
lung infection. Acta Pathol Microbiol Scand (C) Immunol lung infection. A

14 Wisnieski JJ, Todd EW, Fuller RK, et al. Immune complexes and complement abnormalities in patients with cystic fibrosis. Am Rev Respir Dis 1985; 132: 770-6.

15 Jones MM, Seilheimer DK, Pollack MS, Curry M, Crane MM, Dossen RD. Relationship of hypergammaglobulinaemia, circulating immune complexes and histocompatibility antigen profiles in patients with cystic fibrosis. Am Rev Respir Dis 1989; 140: 1636-9.

16 Moss RB, Hsu YP, Lewiston NJ, et al. Association of systemic immune complexes, complement activation, and
antibodies to Pseudomonas aeruginosa lipopolysaccharide antibodies to Pseudomonas aeruginosa lipopolysaccharide
and exotoxin A with mortality in cystic fibrosis. Am Rev and exotoxin A with mortality

17 Fick RB Jr, Robbins RA, Squier SU, Schoderbek WE, Russ WD. Complement activation in cystic fibrosis respiratory fluids: in vivo and in vitro generation of $\mathrm{C} 5 \mathrm{a}$ and chemotactic activity. Pediatr Res 1986; 20: 1258-68.

18 Pantin CFA, Stead RJ, Hodson ME, Batten JC. Prednisolone in the treatment of airflow obstruction in adults with cystic fibrosis. Thorax 1986; 41: 34-8.

19 Auerbach HS, Williams M, Kirkpatrick JA, Cotten HR Alternate day prednisolone reduces the morbidity and
improves pulmonary function in cystic fibrosis. Lancet 1985; ii: 686-8.

20 Knudsen PJ, Dinarello CA, Strom TB. Glucocorticoids inhibit transcriptional and post-transcriptional expression of interleukin-1 in U937 cells. F Immunol 1987; 139: 4129-34.

21 Gillis S, Crabtree GR, Smith KA. Glucocorticoid-induced inhibition of T cell growth factor production I. $\mathcal{f}$ Immunol 1979; 123: 1624-31.

22 Gillis S, Crabtree GR, Smith KA. Glucocorticoid-induced inhibition of $\mathrm{T}$ cell growth factor production II. $\mathcal{F}$ Immunol 1979; 123: 1632-8.
23 Horst HJ, Flad HD. Corticosteroid/interleukin-2 interactions: inhibition of binding of interleukin-2 to interleukin2 receptors. Clin Exp Immunol 1987; 68: 156-62.

24 Greally P, Hussain MJ, Vergani D, Price JF. Serum interleukin- $1 \alpha$ and soluble interleukin-2 receptor concentrations in cystic fibrosis. Arch Dis Child 1993; 68: 785-7.

25 Corey $\mathbf{M}$, Levison $\mathbf{H}$, Crozier D. Five to seven year course of pulmonary function in cystic fibrosis. Am Rev Respir Dis of pulmonary function in

26 Lewiston NJ, Moss RB. Circulating immune complexes decrease during corticosteroid therapy in cystic fibrosis. Pediatr Res 1982; 4: 354A.

27 Moore S, Strieter RM, Standiford TJ, Burdick MD, Kinkel SL. Expression and regulation of human alveolar macrophage derived interleukin-1 receptor antagonist. Am $\mathcal{F}$ Respir Cell Mol Biol 1992; 6: 569-75.

28 Roubin LA, Jay G, Nelson DL. The released interleukin receptor binds interleukin-2 efficiently. F Immunol 1986 137: $3841-4$

29 Sebaldt RJ, Sheller JR, Oates JA, Roberts LJ, Fitzgerald GA Inhibition of eicosanoid synthesis by glucocorticoids in humans. Proc Natl Acad Sci USA 1990; 87: 6974-8.

30 Dworski R, Fitzgerald GA, Sheller JR. Systemic administration of steroids does not alter eicosanoid levels in asthmatic airways. Am Rev Respir Dis 1992; 145: A39.

31 Greally P, Sampson AP, Piper PJ, Price JF. The influence of glucocorticoids on lung function and sputum leukotriene levels in children with cystic fibrosis. Am Rev Respir Dis 1992; 145: A118.

32 Almawi WY, Sewell KL, Zanker B, Hadro ET, Strom TB Mode of action of the glucocorticoids as immunosuppressant agents. In: Dinarello CA, ed. Progress in leucocyte biology: molecular and cellular biology of cytokines. WileyLiss, 1990: 321-6.

33 Kharazmi A. Interactions of Pseudomonas aeruginosa with the cells of the immune system. Antibiot Chemother 1989; 42: 42-9.

34 Berger $M$. Inflammation in the lung in cystic fibrosis: a vicious cycle that does more harm than good? (In Moss RB, ed. Cystic fibrosis.) Clin Rev Allergy 1990; 7 119-40.

35 Rosenstein BJ, Eigen H. Risks of alternate day prednisolone in patients with cystic fibrosis. Pediatrics $1991 ; 87: 245-6$.

36 Dagli E, Warner JA, Besley CR, Warner JO. Raised soluble interleukin-2 receptor concentrations in cystic fibrosis patients with and without evidence of lung disease. Arch Dis Child 1992; 67: 479-81. 